\title{
Cultural Capital and Educational Inequality: A Counterfactual Analysis
}

\author{
Mads Meier Jæger, Kristian Karlson
}

University of Copenhagen

Abstract: We use National Longitudinal Survey of Youth 1979 (NLSY79) data and a counterfactual approach to test the macro-level implications of cultural reproduction and cultural mobility theory. Our counterfactual analyses show that the observed socioeconomic gradient in children's educational attainment in the NLSY79 data would be smaller if cultural capital was more equally distributed between children whose parents are of low socioeconomic status (SES) and those whose parents are of high SES. They also show that hypothetically increasing cultural capital among low-SES parents would lead to a larger reduction in the socioeconomic gradient in educational attainment than reducing it among high-SES parents. These findings are consistent with cultural mobility theory (which argues that low-SES children have a higher return to cultural capital than high-SES children) but not with cultural reproduction theory (which argues that low-SES children have a lower return to cultural capital). Our analysis contributes to existing research by demonstrating that the unequal distribution of cultural capital shapes educational inequality at the macro level.

Keywords: cultural capital; educational inequality; cultural reproduction; cultural mobility; counterfactual analysis; Bourdieu

Citation: Jæger, Mads Meier, and Kristian Karlson. 2018. "Cultural Capital and Educational Inequality: A Counterfactual Analysis." Sociological Science 5: 775795.

Received: September 5, 2018

Accepted: November 7, 2018

Published: December 12, 2018

Editor(s): Jesper Sørensen, Kim Weeden

DOI: $10.15195 /$ v5.a33

Copyright: (C) 2018 The Author(s). This open-access article has been published under a Creative Commons Attribution License, which allows unrestricted use, distribution and reproduction, in any form, as long as the original author and source have been credited. (0)(1)

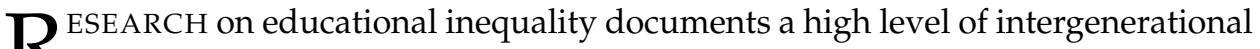
$\mathrm{R}$ persistence in educational outcomes. Among the different theories proposed to explain this persistence, Bourdieu's theory of cultural reproduction is one of the most influential (Bourdieu 1977a, 1984; Bourdieu and Passeron 1990). Bourdieu argued that those in advantaged socioeconomic positions transmit cultural capital (familiarity with high-status cultural signals) to their children, who in turn convert this capital into educational and socioeconomic success. As a consequence, cultural capital is assumed to be a key mechanism through which educational inequality is maintained.

But what do we know about the role of cultural capital in shaping educational inequality? Not much, we argue in this article, and this is an important limitation given the prominent position of the theory of cultural reproduction in existing research. Most research focuses on estimating the direct effect of cultural capital on educational success and reports that possessing more cultural capital leads to more success (typically measured by academic achievement or educational attainment; this literature is reviewed by Jæger and Breen [2016], Kingston [2001], Sullivan [2002], and van de Werfhorst [2010]). However, although this research shows that cultural capital affects educational success at the micro level, it does not address the extent to which cultural capital shapes educational inequality at the macro level. Results from other research can be used to make predictions about the role of cultural capital in shaping educational inequality. First, parents transmit cultural capital to their children (Jæger and Breen 2016; Kraaykamp and van Eijck 2010; Yaish 
and Katz-Gerro 2012). Second, parents of high socioeconomic status (SES) transmit more cultural capital than those of low SES, thereby leading to an SES gradient in children's cultural capital (Lareau 2003; Roksa and Potter 2011; Weininger, Lareau, and Conley 2015). Third, children's cultural capital has a positive effect on their educational success (Gaddis 2013; Jæger 2011). Despite being indirect, these pieces of evidence suggest that cultural capital shapes educational inequality at the macro level.

In this article, we provide new and direct evidence on the extent to which cultural capital shapes educational inequality at the macro level. We draw on Bourdieu's (1977a, 1984) theory of cultural reproduction (CR) and on DiMaggio's (1982) theory of cultural mobility (CM) to conceptualize how an SES gradient in parents' cultural capital inputs in children, and an SES gradient in the return to cultural capital, would affect the socioeconomic gradient in children's educational attainment. We move beyond traditional mediation analysis (which analyzes how much of the direct association between parents' SES and children's educational attainment at the micro level is mediated by cultural capital) and use a counterfactual approach. The key benefit of the counterfactual approach is that we can analyze the role of cultural capital in shaping educational inequality at the macro level. We ask the following: To what extent does the socioeconomic gradient in children's educational attainment (which we measure by using the difference in the years of schooling that high- and low-SES children complete) depend on parents' cultural capital inputs in children, and how would this gradient change if high- and low-SES parents provided different cultural capital inputs? The counterfactual approach allows us to compare the predicted outcomes of the CR and CM theory and offers three analytical advantages.

First, the counterfactual approach allows us to address the consequences for children's educational attainment of parents' differential cultural capital inputs at the macro (or population) level. This means that we may analyze the effect of the unequal provision of, and return to, cultural capital inputs in the parent generation on overall educational inequality in the child generation. This question is at the core of the $\mathrm{CR}$ and $\mathrm{CM}$ theories but has not been addressed directly in previous research.

Second, the counterfactual approach provides a framework for analyzing the intensity of the unequal provision of cultural capital because we can study how marginal changes in parents' cultural capital inputs would affect the socioeconomic gradient in children's educational attainment. For example, what would happen if high- and low-SES parents, or parents who provide high or low cultural capital inputs, changed their cultural capital inputs? We propose several counterfactual scenarios and evaluate the empirical consequences of the CR and CM theory at the macro level. According to the CR theory, low-SES children benefit less from their cultural capital than high-SES children because they tend to be in schooling environments that do not reward cultural capital. In our counterfactual approach, this asymmetry in the return to cultural capital implies that a marginal increase in cultural capital inputs among low-SES parents would lead to a smaller reduction in the socioeconomic gradient in educational attainment than a marginal decrease among high-SES parents. By contrast, in the CM theory, cultural capital is assumed 
to benefit high- and low-SES children equally (i.e., there is no asymmetry) or to benefit low-SES children more than high-SES children. The implication of the CM theory is then that a marginal increase in cultural capital inputs among low-SES parents would have the same (or a stronger) equalizing effect in the population than a marginal reduction among high-SES parents.

Third, we may use the counterfactual approach to analyze how (in addition to the differences in educational inequality implied by the CR and CM theories) changes in the socioeconomic gradient in cultural capital inputs originating from other trends (for example, changes in cultural hierarchies [Fishman and Lizardo 2013], rising income inequality [Lancee and van de Werfhorst 2012], and policy interventions [Kisida, Green, and Bowen 2014; Nagel, Damen, and Haanstra 2010]) would affect educational inequality. This means that the counterfactual approach can be used to compare the outcomes of theories, trends, or policies that change the composition of cultural capital in the population.

Our empirical analysis is based on data from the National Longitudinal Survey of Youth 1979 (NLSY79) and its Child and Young Adult (CYA) supplement. The NLSY79 provides longitudinal data on cultural capital, which enables us to construct a summary measure of parents' cultural capital inputs in children throughout childhood (ages 0-14 years). We use endogenous switching regression to model the likelihood that parents belong to a group that provides high cultural capital inputs or to a group that provides low inputs, and we compare factual and counterfactual predictions of children's educational attainment within each group.

Our empirical analysis shows that factual differences in cultural capital inputs between high- and low-SES parents lead to a nontrivial socioeconomic gradient in children's educational attainment (we estimate this gradient to be around 1.3 years of schooling). When we compare the outcomes of the CR and CM theories in our counterfactual approach, we find that a scenario in which we increase cultural capital inputs among low-SES parents (who also provide low cultural capital inputs) would lead to a significantly larger reduction in the socioeconomic gradient in educational attainment compared to a scenario in which we reduce cultural capital inputs among high-SES parents (who also provide high inputs). These results do not fit the predictions from the CR theory but are broadly consistent with the CM theory, arguing that the return to cultural capital is higher for low-SES children than for high-SES children.

\section{Theoretical Background}

This section presents our theoretical framework. We begin by introducing Bourdieu's theory of cultural reproduction, including the concept of cultural capital and its role in creating educational inequality. We then present DiMaggio's theory of cultural mobility and describe ways in which cultural capital may operate differently in high- and low-SES families and schooling environments. We end the section by presenting a simple counterfactual model that we use to develop a set of empirical hypotheses. 


\section{The Concept of Cultural Capital}

Bourdieu $(1977 b, 1984,1986)$ defined cultural capital as familiarity with the highstatus cultural codes that exist in a society. He argued that cultural capital is a resource that is equivalent to economic resources (referred to as economic capital) and social networks (referred to as social capital). Cultural capital is possessed by families and individuals and is transmitted from parents to children through investments and socialization. Cultural capital may also be acquired outside the family of origin (for example, via peers or social networks [Bourdieu 1984; Lizardo 2006]).

Being a form of capital, cultural capital can be exchanged for other economic and social assets. Based on Bourdieu, Lamont and Lareau (1988:156) define cultural capital, and its function, as "(...) institutionalized, i.e., widely shared, high status cultural signals (attitudes, preferences, formal knowledge, behaviors, goals, and credentials) used for social and cultural exclusion." This definition highlights that cultural capital can be converted into other types of capital and that it is a positional good, which can be used to exclude others from positions of material or symbolic advantage. Treating cultural capital as a positional good is important in this article, as we analyze how hypothetically changing the distribution of cultural capital in the population (which might change the relative value of cultural capital) would affect educational inequality.

\section{Cultural Reproduction Theory}

We now present Bourdieu's cultural reproduction (CR) theory. According to Bourdieu, cultural capital exists in an embodied state (linguistic competence, taste, cultural knowledge, etc.), an objectified state (cultural goods, art, books, etc.), and an institutionalized state (educational credentials) (Bourdieu 1977b, 1986; Bourdieu and Passeron 1990). It contributes to educational inequality in all three states. Parents transmit cultural capital to children either by actively transmitting cultural capital or by unintentionally exposing children to objectified and embodied cultural capital in the home (Kraaykamp and van Eijck 2010; Lareau 2003). The relative importance of parents' active investments in transmitting cultural capital as opposed to passive exposure is not clear in Bourdieu's writings (Jæger and Breen 2016), and in this article, we use the term cultural capital inputs to capture the joint outcome of both processes. Children internalize parents' cultural capital, which becomes embodied cultural capital and an integral part of their dispositions and behaviors.

Bourdieu argues that cultural capital is a key mechanism through which educational inequality is preserved. Society is comprised of different fields (that is, arenas in which different types of capital have different value [Bourdieu 1986]). The field of education is an important subfield, and it is biased toward ascribing positive qualities onto those who possess cultural capital. This bias arises from cultural capital unintentionally being associated with membership of elite-status groups, and it results in those possessing it receiving favorable treatment by teachers and being more successful in the educational system. As a consequence, in the CR theory, cultural capital enhances educational inequality because high-SES parents possess more cultural capital than low-SES parents, they transmit more of it to their 
children, and their children are more likely to be in schooling environments that recognize and reward cultural capital.

\section{Cultural Mobility Theory}

DiMaggio's (1982) cultural mobility (CM) theory challenges Bourdieu's CR theory by arguing that a gradual erosion of the traditional status order means that the link between cultural capital and membership in elite-status groups is much weaker than it used to be (Daloz 2013; Lizardo and Skiles 2015). This means that cultural capital, which is a signal of familiarity with high-status culture but is no longer a signal of membership in a high-status group (as in the CR theory), may benefit highand low-SES children equally. The consequence of this argument is that educational inequality arises from a socioeconomic gradient in parents' cultural capital inputs in children rather than from a socioeconomic gradient in the return to cultural capital (in the CR theory, the return to cultural capital is assumed to be higher for high-SES children than for low-SES children). Moreover, according to the CM theory, the return to cultural capital may in fact be higher for low-SES children than for highSES children because the schooling environments that low-SES children inhabit tend to have less cultural capital and, if possessed, it is easier for children who possess cultural capital to convert it into educational success (Andersen and Jæger 2015; Aschaffenburg and Maas 1997; Dumais 2006). The CM theory thus argues that the value of cultural capital as a positional good is higher for low-SES students than for high-SES students. Overall, the predictions from the CM theory contrast with those from the CR theory, and in the next section, we use our counterfactual approach to address the implications of each theory for educational inequality.

\section{Hypotheses}

We now propose a simple conceptual framework that enables us to compare the predictions of the CR and CM theories. The main benefit of this framework is that we may distinguish different mechanisms through which cultural capital affects educational inequality in the population. Our model builds on three assumptions. First, we assume that parents belong to one of two SES groups: high or low. ${ }^{1}$ Second, we assume that parents belong to one of two states with regard to their cultural capital inputs in children: a high-input state or a low-input state. Third, we assume that parents in the high-SES group are more likely to belong to the high-input state than to the low-input state, thereby leading to a socioeconomic gradient in cultural capital inputs. The last assumption has strong empirical backing in existing research (Kraaykamp and van Eijck 2010; Yaish and Katz-Gerro 2012) and is also supported by our NLSY79 data. Based on these assumptions, we may use empirical data to estimate the actual SES gradient in children's educational attainment and to analyze how this gradient would change if parents' cultural capital inputs were distributed differently in the population. We now summarize the predictions from the CR and $\mathrm{CM}$ theories.

The CR theory predicts that the socioeconomic gradient in children's educational attainment would be smaller than it actually is if cultural capital inputs were more 
equally distributed between high- and low-SES parents. Moreover, given that lowSES children are assumed to benefit less from their cultural capital than high-SES children, the CR theory predicts that a marginal increase in cultural capital inputs among low-SES parents would lead to a smaller reduction in educational inequality than a marginal decrease among high-SES parents. This is our first hypothesis (H1).

The CM theory predicts (as does the CR theory) that a more equal distribution of cultural capital in the population would lead to lower educational inequality. However, it differs from the CR theory by arguing that cultural capital yields the same or a higher return for low-SES children because these children tend to be in schooling environments in which cultural capital is more valuable. Based on these arguments, we propose two hypotheses. The first hypothesis $(\mathrm{H} 2 \mathrm{a})$ is that a marginal increase in cultural capital inputs among low-SES parents would lead to the same reduction in overall educational inequality as a marginal decrease among high-SES parents. This hypothesis assumes that the return to cultural capital has no socioeconomic gradient. The second hypothesis $(\mathrm{H} 2 \mathrm{~b})$ is that a marginal increase in cultural capital inputs among low-SES parents would lead to a larger reduction in educational inequality than a marginal decrease among high-SES parents. This hypothesis assumes that the return to cultural capital is higher for low-SES children than for high-SES children. To test the implications of the CM and CR theories, we specify three counterfactual scenarios that examine how changing parents' cultural capital inputs affects educational inequality at the population level.

Scenario A: Equalization from below. In this scenario, we address the populationlevel outcomes of increasing cultural capital inputs among low-SES parents who provide low cultural capital inputs. Specifically, this scenario evaluates the extent to which a hypothetical marginal increase in low-SES and low-input parents' inputs would affect the SES gradient in children's years of completed schooling (while holding all other parental inputs constant). Substantively, in this scenario, we assess what would happen if a marginal fraction of parents in the most disadvantaged (i.e., low-SES and low-input) group changed their cultural capital inputs from low to high. Combined with the scenario presented next, we use Scenario A to compare the predictions of the $\mathrm{CR}$ and $\mathrm{CM}$ theories.

Scenario B: Equalization from above. In this scenario, we address the populationlevel outcomes of decreasing (rather than increasing) parents' cultural capital inputs. In contrast to Scenario A, this scenario evaluates the effect of a marginal decrease in high-SES and high-input parents' cultural capital inputs (while holding all other parental inputs constant). Substantively, in this scenario, we assess what would happen if a marginal fraction of parents in the most advantaged group (high-SES and high-input parents) reduced their inputs from high to low. As explained above, the CR theory predicts that Scenario A would lead to a smaller decrease in the observed socioeconomic gradient in educational attainment than Scenario B (H1), whereas the $\mathrm{CM}$ theory predicts that Scenarios $\mathrm{A}$ and $\mathrm{B}$ would lead to the same $(\mathrm{H} 2 \mathrm{a})$ or to a larger $(\mathrm{H} 2 \mathrm{~b})$ reduction in educational inequality.

We recognize that a scenario that decreases cultural capital inputs among the most advantaged group is probably not very realistic. Nonetheless, we use it here to analyze the impact of changing cultural capital inputs on educational inequality at the population level, and moreover, we notice that it is logically equivalent to 
analyzing whether an increase in cultural capital inputs among the most advantaged group would lead to as large of an increase in educational inequality as the implied decrease in Scenario B.

Scenario C: Equalization by universal intervention. In this scenario, we address the population-level outcomes of a marginal increase in cultural capital inputs among all parents-irrespective of SES—who provide low cultural capital inputs (while holding all other parental inputs constant). We include this scenario to study a hypothetical intervention that targets all low-input parents irrespective of SES (we also compare results with those we find for Scenarios A and B). We expect this scenario to lead to a reduction in educational inequality because low-SES parents on average provide lower cultural capital inputs than high-SES parents, and as a consequence, their children are particularly likely to benefit from higher cultural capital inputs.

\section{Data and Methods}

\section{Sample}

Our empirical analysis is based on data from the National Longitudinal Survey of Youth 1979 (NLSY79) and its Child and Young Adult (CYA) supplement. The NLSY79 is a national sample of 12,686 individuals aged 14 to 22 years in 1979. These individuals have been surveyed annually through 1994 and biennially through 2012. The CYA supplement is a separate survey of all children born to female respondents in the NLSY79 collected biennially from 1986 through 2012. As of 2012, the CYA supplement has covered about 11,500 children born to about 5,000 mothers. Combining these two surveys provides us with longitudinal information on (a) the life courses of NLSY79 women who eventually become mothers, (b) the cultural capital that mothers possess and transmit to their children, and (c) the educational attainment of these children as they transition into adulthood.

We restrict our analytical sample in two ways. First, because our outcome variable is educational attainment, we restrict the sample to the 5,974 CYA participants who were at least 25 years of age at the time of interview. Second, we omit participants with systematic missing responses on the variables included in the analysis. ${ }^{2}$ The resulting analytical sample comprises 2,986 children born between 1975 and 1987 to 1,965 mothers. This sample is not representative of children born between 1975 and 1987 but rather of children born in this period to mothers who themselves were born between 1957 and 1965. Analyses not reported here show that compared to all children born to NLSY79 mothers, those born between 1975 and 1987 are somewhat more socially disadvantaged (detailed information available upon request). To address sample selection, we combine the sampling weight provided in the CYA with a weight that we construct based on the inverse probability of being included in the final analytical sample. ${ }^{3}$ Moreover, we correct standard errors for the clustering of children within mothers. Table 1 shows descriptive statistics for all variables included in the analysis. 
Table 1: Descriptive statistics (means and standard deviations).

\begin{tabular}{|c|c|c|c|c|c|c|}
\hline & \multicolumn{2}{|c|}{ Total sample } & \multicolumn{4}{|c|}{ Parental SES } \\
\hline & \multirow[b]{2}{*}{ Mean } & \multirow[b]{2}{*}{ SD } & \multicolumn{2}{|c|}{ Low } & \multicolumn{2}{|c|}{ High } \\
\hline & & & Mean & SD & Mean & $\mathrm{SD}$ \\
\hline Child's years of schooling & 13.22 & 2.35 & 12.55 & 2.21 & 13.90 & 2.23 \\
\hline \multicolumn{7}{|l|}{ Cultural capital inputs: } \\
\hline High (reference low) & 0.50 & - & 0.33 & - & 0.67 & \\
\hline Parental SES & 0.00 & 1.00 & -0.72 & 0.53 & 0.72 & 0.82 \\
\hline $\begin{array}{l}\text { Mother married } \\
\text { (reference not married) }\end{array}$ & 0.55 & - & 0.43 & - & 0.67 & - \\
\hline Number of siblings & 2.2 & 1.03 & 2.37 & 1.16 & 2.06 & 0.86 \\
\hline \multicolumn{7}{|l|}{ Race: } \\
\hline Black & 0.23 & - & 0.30 & - & 0.17 & - \\
\hline Hispanic & 0.10 & - & 0.13 & - & 0.07 & - \\
\hline Other (reference) & 0.67 & - & 0.57 & - & 0.76 & - \\
\hline Male (reference female) & 0.52 & - & 0.51 & - & 0.54 & - \\
\hline Mother's year of birth & $1,960.8$ & 2.2 & $1,961.2$ & 2.2 & $1,960.4$ & 2.2 \\
\hline Child's year of birth & $1,982.8$ & 2.6 & $1,982.5$ & 2.5 & $1,983.2$ & 2.6 \\
\hline Child's cognitive ability & 0.00 & 1.00 & -0.32 & 1.01 & 0.32 & 0.88 \\
\hline Grandparents' years of schooling & 10.29 & 3.54 & 9.27 & 3.38 & 11.31 & 3.40 \\
\hline Mother's expected years of schooling & 13.23 & 2.14 & 12.35 & 1.88 & 14.11 & 2.00 \\
\hline $\mathrm{N}$ (individuals) & \multicolumn{2}{|c|}{2,986} & \multicolumn{2}{|c|}{1,543} & \multicolumn{2}{|c|}{1,443} \\
\hline $\mathrm{N}$ (mothers) & \multicolumn{2}{|c|}{1,965} & \multicolumn{2}{|c|}{1,000} & \multicolumn{2}{|c|}{996} \\
\hline Effective sample size ${ }^{a}$ & \multicolumn{2}{|c|}{-} & \multicolumn{2}{|c|}{1,214} & \multicolumn{2}{|c|}{1,181} \\
\hline
\end{tabular}

Note: Combined weight applied (weight provided in CYA multiplied with the inverse probability of being in the sample conditional on race, gender, number of siblings, mother's birth year, offspring's birth year, and family income averaged over childhood from 0 through 15 years of age). ${ }^{\text {a }}$ Effective sample size is calculated as $\mathrm{Gg} /(1+(\mathrm{g}-1) \rho)$, where "G" is the number of mothers, " $\mathrm{g}$ " is the average number of children per mother, and " $\rho$ " is the intraclass correlation computed from an empty variance components model.

\section{Dependent Variable}

Our dependent variable is CYA children's completed years of schooling. Because we have multiple measures of this variable for most children, we use the highest number ever reported.

\section{Cultural Capital Inputs}

There are ongoing discussions about how to best measure cultural capital. We use a range of empirical indicators that have all been used in previous research to capture different aspects of cultural capital. We use these indicators to construct a summary scale that captures parents' overall cultural capital inputs in each of their children throughout childhood. Table 2 groups the empirical indicators into three age groups: 0 to 5,6 to 9 , and 10 to 14 years.

The first aspect of cultural capital is familiarity with legitimate culture (Aschaffenburg and Maas 1997; DiMaggio 1982), which we capture with three indicators measuring how often the child is taken for an outing, to a museum, and to a theatre and/or music performance. The second aspect is reading (de Graaf, de Graaf, and Kraaykamp 2000; Gaddis 2013), which we capture with three indicators measuring 
Table 2: Overview of cultural capital indicators by age group.

\begin{tabular}{|c|c|c|c|}
\hline & \multicolumn{3}{|c|}{ Age group } \\
\hline & $0-5$ & $6-9$ & $10-14$ \\
\hline Taken on an outing regularly & + & & \\
\hline Taken to a museum regularly & + & + & + \\
\hline Taken to a theatre and/or music performance regularly & & + & + \\
\hline Child has more than 10 books & + & & \\
\hline Child has more than 20 books & & + & + \\
\hline Mother reads to the child regularly & + & + & \\
\hline Musical instrument in the home to use & & + & + \\
\hline Family encourages hobbies & & + & + \\
\hline Attends special lessons or extracurricular activities & & + & + \\
\hline Discusses TV programs with parents & & + & + \\
\hline
\end{tabular}

Note: All indicators are binary.

whether the child has more than 10 and more than 20 books and how often the mother reads to the child. The third aspect is extracurricular activities (Covay and Carbonaro 2010; Kaufman and Gabler 2004; Lareau 2003), which we capture with three indicators measuring whether there is a musical instrument in the home that the child can use, whether parents encourage hobbies, and whether the child attends special lessons or extracurricular activities. The fourth aspect is cultural communication (Georg 2004; Lee and Bowen 2006; Tramonte and Willms 2010), which we capture with a single indicator measuring how often the child discusses television (TV) programs with parents.

We construct the summary scale of parents' cultural capital inputs using a two-step principal component analysis (PCA). ${ }^{4}$ PCA is a methodology that uses the covariance between the different cultural capital indicators to identify a latent variable that summarizes overall cultural capital inputs. In the first step, we perform a PCA on the cultural capital indicators for each age group separately and retain the first principal component (PC) from each group. This procedure yields three variables that summarize cultural capital inputs in each age group. In the second step, we perform a PCA on the retained PCs from each age group and retain the first PC from this analysis. ${ }^{5}$ The PC from the second step is our summary indicator of parents' cultural capital inputs in children throughout childhood (age 0-14 years), with higher values indicating higher inputs. In the empirical analysis, we divide parents into two equally sized groups (cut at the median of the summary indicator) that capture low and high cultural capital inputs. This coding scheme is consistent with our counterfactual setup, which treats parents as belonging to either a low- or high-input group. ${ }^{6}$

\section{Parental SES}

We construct a summary scale that captures parents' SES. As with cultural capital, we use multiple indicators and PCA to construct this scale. Specifically, we retain the first PC from a PCA that includes the following indicators: annual family 
income averaged over childhood (from age 0 through 15 years), highest socioeconomic position ever reported by a parent (Duncan Socioeconomic Index [SEI]), and mother's year of completed schooling. We treat this PC (which accounts for 51 percent of the total variance in the items) as a summary scale of parents' SES. As was also the case with the indicator of cultural capital, we split this variable into two equally sized groups (cut at the median) to capture low- and high-SES parents.

\section{Control Variables}

We include a set of control variables, including mother's marital status (dummy for intact family), number of siblings, race, and gender. Because the CYA sample covers children who are born at different times to mothers who are born at different times, we also control for the year of birth of both the child and mother. In addition to these control variables, our statistical models also include two variables that are assumed to affect children's educational attainment only via parents' cultural capital inputs. These variables are required for identifying our statistical models and are known as "exclusion restrictions" (see further details in the online supplement). We use two variables that capture different aspects of the mother's own family background and that we argue are informative about mothers' later parenting style and appreciation of cultural capital (Mare 2011; Roksa and Potter 2011).

The first variable is maternal grandparents' highest years of completed schooling. The rationale for including this variable is that we expect it to capture some aspects of the cultural environment in which the mother grew up and that shaped her cultural preferences and cultural capital (Kraaykamp and van Eijck 2010). As research on multigenerational effects shows no direct effect of grandparents' attainment on grandchildren's attainment (other than that going through parents' attainment [e.g., Warren and Hauser 1997]), we expect this variable to affect children's educational attainment via the parents' cultural capital inputs (net of the other covariates in the model, including parental SES and sociodemographic characteristics).

The second variable is the mother's self-report of how many years of schooling she expected to complete (measured between age 14 and 21 years). The rationale for including this variable is that among mothers from similar family backgrounds and with similar sociodemographic characteristics, educational expectations may feed into the cultural rearing environments that mothers eventually provide for their own children (Lareau 2003). This would be the case if these expectations come to guide-in an embodied form-not only the achievement goals that a mother sets for her children but also the means though which she expects to complete these goals-in this case, cultural capital.

\section{Methodological Design}

Our empirical framework consists of two interlinked components. The first component is a model that estimates factual and counterfactual distributions of children's educational attainment using the NLSY79 and CYA data. We use endogenous switching regression models (ESRMs) for this purpose. The second component is a counterfactual analysis in which, building on the predictions from the ESRMs, we calculate the socioeconomic gradient in children's educational attainment under 
Table 3: Overview of predictions.

\begin{tabular}{lcc}
\hline & \multicolumn{2}{c}{ Cultural Capital Input State } \\
& Low & High \\
& $E\left(y_{2} \mid z\right)$ & $E\left(y_{1} \mid z\right)$ \\
\hline Actual Input State & & \\
Low $(\mathrm{z}=0)$ & A & B \\
High $(\mathrm{z}=1)$ & (Factual) & (Counterfactual) \\
& C & D \\
& (Counterfactual) & (Factual) \\
\hline
\end{tabular}

each of the three hypothetical scenarios that we propose. We are mainly interested in the second component because it provides the empirical basis for analyzing how hypothetical changes in cultural capital inputs would affect overall educational inequality. As a consequence, we provide a nontechnical presentation of the ESRM in the main text and relegate technical details to the online supplement.

The ESRM considers two outcomes jointly: (1) the likelihood that high- and low-SES parents belong to the high- and low-cultural capital input state and (2) the effect of being in the high- and low-cultural capital input state on children's educational attainment (Heckman 1990; Maddala 1983; Mare and Winship 1988). We use the ESRM to make counterfactual predictions of how much education children from different SES backgrounds would have completed if they had been exposed to a different cultural capital input state (high or low) than the one they were exposed to. We provide an overview of the relevant predictions from the ESRMs in Table 3 and provide formulae for deriving these predictions in the online supplement.

Cell A in Table 3 captures the expected years of completed schooling for children whose parents belong to the group that provides low cultural capital inputs. This expectation is observed in the data (i.e., it is factual). By contrast, cell B captures the expected years of completed schooling that children who were exposed to the low-input state would have had if they had been exposed to the high-input state instead. This expectation is counterfactual. By the same logic, cell D captures the factual years of completed schooling for children who were exposed to the high-input state, whereas cell $C$ captures the expected years of schooling had they been exposed to the low-input state instead.

We use the predictions from the ESRMs to calculate children's expected years of completed schooling under different assumptions about the distribution of cultural capital inputs in the population (as described in scenarios A-C). This approach enables us to evaluate the predictions of the CR and CM theories. We conduct the analyses separately for high- and low-SES parents in order to assess the consequences of each scenario for socioeconomic gradients in children's educational attainment. 


\section{Results}

This section presents the main empirical results. We do not discuss results from the ESRMs in this section (we do this in the online supplement) but instead focus on the factual and counterfactual predictions from the ESRMs that we use to evaluate the CR and CM theories. We use the ESRMs to calculate empirical predictions of children's factual and counterfactual educational attainment in the low- and high-SES groups, respectively. We then use these predictions to test the hypotheses that follow from the $\mathrm{CR}$ and $\mathrm{CM}$ theories regarding the socioeconomic gradient in children's educational attainment.

Table 4 uses the empirical estimates from the ESRMs to predict the average years of completed schooling for children whose parents belong to the high and low (factual and counterfactual) cultural capital input states, respectively. This means that the numbers in the table are our empirical estimates of the different cells in Table 3. Panel A shows factual and counterfactual outcomes for children of low-SES parents in the low- and high-input states (and the outcome for all low-SES parents). It shows that the average years of completed schooling among children whose parents were in the low-input state was 12.3. This is the factual outcome in the low-input state (cf. cell A in Table 3). However, based on our ESRMs, we calculate that if these (low-SES) parents had instead been in the high-input state (cell B in Table 3), their children would on average have completed 15.4 years of schooling (i.e., a difference of 3.1 years). Similarly, our model predicts that children of lowSES parents in the high-input state on average complete 12.9 years of schooling (cell D) but would have completed 10.1 years if their parents had instead been in the low-input state (cell C) (i.e., a difference of 2.8 years). This result means that holding other factors constant, hypothetically reallocating low-SES parents from the low-input state to the high-input state (and vice versa) would lead to a nontrivial increase (decrease) in their children's educational attainment.

Panel B in Table 4 summarizes the corresponding predictions for high-SES parents. We find a similar pattern for those who belong to the low-input state: Reallocating these parents to the high-input state would lead to a significant increase in their children's educational attainment, approximately 3.2 years of schooling. Furthermore, reallocating high-SES parents from the high-input state to the low-input state would lead to only a small decrease in their children's educational attainment, approximately 0.8 years of schooling. Thus, the results presented in Table 4 illustrate that, within SES groups, reallocating parents to the counterfactual cultural capital input state would have a nontrivial effect on their children's educational attainment.

The results in Table 4 are broadly consistent with the CM theory in that the average effect of cultural capital on educational attainment, which is summarized in the final row of each panel in the table, is almost twice as large for the low-SES group (3.0) as for the high-SES group (1.6). Although this average difference is not statistically significant at a 5 percent level, it conceals an underlying asymmetry in the return to cultural capital that previous research has not demonstrated. As shown in the final column in Panel B, children of high-SES and low-input parents would benefit from high cultural capital inputs to the same extent as all low-SES children 
Table 4: Average adjusted predictions of children's years of completed schooling from ESRMs by parental SES.

\begin{tabular}{|c|c|c|c|c|c|}
\hline \multicolumn{6}{|c|}{ Panel A: Low Parental SES } \\
\hline & & \multicolumn{2}{|c|}{ Cultural Capital Inputs } & \multicolumn{2}{|c|}{ Difference } \\
\hline & & Low & High & & SE \\
\hline Low & & 12.3 & 15.4 & $3.1^{\dagger}$ & 0.92 \\
\hline High & & 10.1 & 12.9 & $2.8^{\dagger}$ & 0.74 \\
\hline \multirow{4}{*}{ All } & & 11.6 & 14.6 & $3.0^{+}$ & 0.86 \\
\hline & Panel B: High Parental SES & & & & \\
\hline & & \multicolumn{2}{|c|}{ Cultural Capital Inputs } & \multicolumn{2}{|c|}{ Difference } \\
\hline & & Low & High & & SE \\
\hline Low & & 13.3 & 16.5 & $3.2^{+}$ & 0.55 \\
\hline High & & 13.3 & 14.1 & $0.8^{\dagger}$ & 0.19 \\
\hline All & & 13.3 & 14.9 & $1.6^{+}$ & 0.26 \\
\hline
\end{tabular}

Note: Average adjusted prediction refers to the average of the predictions for each combination of values on the explanatory variables. Standard errors (SEs) are estimated by using the bootstrap with 1,000 replications. ${ }^{+} p \leq 0.01$ (two-tailed tests).

(i.e., their expected years of completed schooling would increase by roughly 3 years if they were exposed to the high-input state instead). By contrast, reallocating children from the (factual) high-SES and high-input group to the (counterfactual) high-SES and low-input group would only decrease the average years of completed schooling by roughly 0.8 years. This means that for this group, the "penalty" for being reallocated to the low-input state is much lower than for the other groups. The differences between the latter group's estimate and the other groups' estimates are all statistically significant at a 5 percent level. We return to this asymmetry below and analyze its implications for educational inequality at the population level.

To evaluate how hypothetical changes in cultural capital inputs between SES groups would affect educational inequality in the population, in Table 5, we present the consequences entailed by Scenarios A, B, and C. The CR theory (H1) predicts that increasing cultural capital inputs among low-SES parents (Scenario A) would lead to a smaller reduction in the socioeconomic gradient in children's educational attainment than reducing inputs among high-SES parents (Scenario B). By contrast, the $\mathrm{CM}$ theory predicts that the reduction in educational inequality would be identical in both scenarios $(\mathrm{H} 2 \mathrm{a})$ or would be higher in Scenario A than in Scenario B (H2b). Table 5 summarizes two sets of empirical results: estimates of the marginal effect of reallocating parents from one input state to another on the socioeconomic gradient in children's educational attainment under each counterfactual scenario (left side) and the resulting predicted years of schooling for low- and high-SES children under each scenario (right side).

Under Scenario A (equalization from below), we find that hypothetically increasing the share of low-SES parents that provides low cultural capital inputs (to instead provide high inputs) by 1 percentage point would reduce the socioeconomic gradient in children's educational attainment by 0.02 years of schooling 
Table 5: Marginal effect of cultural capital inputs and predicted years of schooling by parental SES, Scenarios A-C (average adjusted predictions).

\begin{tabular}{|c|c|c|c|c|c|c|}
\hline & \multirow{2}{*}{$\begin{array}{l}\text { Marginal } \\
\text { Effect }^{\mathrm{a}}\end{array}$} & \multicolumn{5}{|c|}{ Predictions } \\
\hline & & $\begin{array}{c}\text { Parental SES: } \\
\text { Low }\end{array}$ & $\begin{array}{c}\text { Parental SES: } \\
\text { High }\end{array}$ & Average & $\begin{array}{c}\text { SES } \\
\text { Difference }^{b}\end{array}$ & $\begin{array}{l}\text { Reduction } \\
\text { from } \\
\text { observed }\end{array}$ \\
\hline Observed & & 12.5 & 13.8 & 13.2 & $1.3^{+}$ & - \\
\hline \multicolumn{7}{|l|}{ Scenario A } \\
\hline 1 & $-0.02^{\dagger}$ & 12.5 & 13.8 & 13.2 & $1.3^{\dagger}$ & $1.6 \%$ \\
\hline 5 & $(0.01)$ & 12.6 & 13.8 & 13.2 & $1.2^{\dagger}$ & $8.0 \%$ \\
\hline 10 & & 12.7 & 13.8 & 13.3 & $1.1^{\dagger}$ & $15.9 \%$ \\
\hline \multicolumn{7}{|l|}{ Scenario B } \\
\hline \% point increase: & & & & & & \\
\hline 1 & $-0.01^{\dagger}$ & 12.5 & 13.8 & 13.2 & $1.3^{+}$ & $0.4 \%$ \\
\hline 5 & $(0.00)$ & 12.5 & 13.7 & 13.2 & $1.2^{\dagger}$ & $2.1 \%$ \\
\hline 10 & & 12.5 & 13.7 & 13.1 & $1.2^{\dagger}$ & $4.1 \%$ \\
\hline \multicolumn{7}{|l|}{ Scenario C } \\
\hline$\%$ point increase: & & & & & & \\
\hline 1 & $-0.01^{*}$ & 12.5 & 13.8 & 13.2 & $1.3^{\dagger}$ & $0.8 \%$ \\
\hline 5 & $(0.01)$ & 12.6 & 13.8 & 13.2 & $1.2^{\dagger}$ & $3.9 \%$ \\
\hline 10 & & 12.7 & 13.9 & 13.3 & $1.2^{\dagger}$ & $7.8 \%$ \\
\hline
\end{tabular}

Note: Standard errors are in parentheses. ${ }^{\text {a }}$ The marginal effect of a change of 1 percentage point in parents' cultural capital input on the SES gradient in children's educational attainment is shown. ${ }^{b}$ Standard errors are estimated by using the bootstrap with 1,000 replications.

${ }^{*} p \leq 0.10,{ }^{+} p \leq 0.01$ (two-tailed tests).

(the estimate of the marginal effect is statistically significant at $p \leq 0.01$ ). The table also shows that under Scenario B (equalization from above), reducing the share of high-SES parents who provide high inputs by 1 percentage point would reduce the socioeconomic gradient by 0.01 year of schooling $(p \leq 0.01)$. The difference between the marginal effects in Scenarios A and B is statistically significantly different $(p \leq$ 0.01). Considered together, these results do not fit the prediction from the CR theory that a marginal increase in cultural capital inputs among low-SES parents would lead to a smaller reduction in educational inequality than a similar decrease in inputs among high-SES parents (H1). However, the empirical results are consistent with the CM theory, arguing that low-SES children have a higher return to cultural capital than high-SES children because they face less competition when converting their cultural capital into educational attainment $(\mathrm{H} 2 \mathrm{~b})$. In other words, our findings fit the idea that increasing cultural capital inputs among low-SES parents leads to a larger reduction in educational inequality because the "exchange rate" with which low-SES children convert their cultural capital into educational attainment (or the value of cultural capital as a positional good) is higher than the one that applies to high-SES children. 
In addition to summarizing marginal effects, Table 5 also quantifies the reduction in the socioeconomic gradient that would follow under each scenario. It shows the predicted years of schooling for children whose parents belong to the high- and lowSES groups and the percent-wise reduction in the socioeconomic gradient relative to the baseline gradient when we change the intensity of cultural capital inputs (using changes of 1,5 , and 10 percentage points as benchmarks). The observed gradient in the population is 1.3 years of schooling. When, in Scenario A, we increase the share of low-SES parents who provide high cultural capital inputs by 1 percentage point (and hold other factors constant), the gradient reduces to slightly less than 1.3 years, or by 1.6 percent. If we increase the share by 5 and 10 percentage points, the reduction is substantially larger (8 percent and 15.9 percent, respectively).

Table 5 also shows, as we would expect, that the quantitative impact of Scenario $B$ is considerably smaller than that of Scenario A. In Scenario B, we find that a reduction in the share of high-SES parents who provide high cultural capital inputs by 1 percentage point would reduce the socioeconomic gradient by 0.4 percent. As discussed above, results from Scenario B thus suggest that the penalty for not providing high cultural capital inputs is lower among high-SES parents than among low-SES parents. This may result from a lower return to cultural capital among high-SES children (possibly because cultural capital is more common in high-SES environments) or from high-SES parents possessing resources other than cultural capital (e.g., wealth or social capital) that offset the negative consequences of a hypothetical reduction in their cultural capital inputs. The latter argument is similar to the logic behind the theory of Effectively Maintained Inequality (Lucas 2001, 2017), which states that as access to higher education (or in this case, cultural capital) increases among low-SES parents, high-SES parents find other means (than cultural capital) to maintain their relative positional advantage.

Table 5 also summarizes results from Scenario $C$ (equalization by universal intervention), in which we increase cultural capital inputs among all parents who provide low inputs (irrespective of SES). The estimated reduction in the socioeconomic gradient in educational attainment is weakly significant $(p \leq 0.10)$ and is substantively lower than what we found in Scenario A. This result means that increasing cultural capital inputs among all low-input parents would reduce educational inequality, but also, the equalizing effect is not as large as when hypothetically increasing cultural capital inputs among low-input parents who also belong to the low-SES group. Moreover, the small effect on inequality of targeting all low-input parents that we find in Scenario $C$ arises from SES not affecting the returns to cultural capital inputs among low-input parents (cf. Table 4). Consequently, the effect is driven by the fact that more low-SES parents than high-SES parents provide low cultural capital inputs. In summary, the results from Scenario $C$ highlight that at the population level, interventions that target the group of parents who provide low cultural capital inputs would be less effective in reducing educational inequality than interventions (as in Scenarios A and B) that target both different SES and different cultural capital input groups. We return to this point in the discussion. ${ }^{7}$ 


\section{Discussion}

This article was motivated by the observation that although Bourdieu's theory of cultural reproduction (CR) was intended to explain educational inequality at the macro level, most research that tests this theory focuses on educational achievement or attainment at the micro level. This means that we know little about the extent to which cultural capital accounts for the socioeconomic gradient in children's educational attainment that exists in most countries or if this gradient is best explained by the $\mathrm{CR}$ theory or the competing cultural mobility $(\mathrm{CM})$ theory.

In the article, we use a counterfactual approach to test the implications of the CR and $\mathrm{CM}$ theories with regard to educational inequality. We argue that because the return to cultural capital is assumed to be higher for high-SES children than for lowSES children in the CR theory, a hypothetical reduction in low-SES parents' cultural capital inputs would lead to a smaller decrease in the socioeconomic gradient in children's educational attainment than a similar reduction among high-SES parents. In contrast, in the CM theory, the return to cultural capital is assumed to be either identical for low- and high-SES children or higher for low-SES children. This means that reducing or increasing cultural capital inputs among high- and low-SES parents would lead to the same reduction in educational inequality, or alternatively, increasing inputs among low-SES parents would have a larger equalizing effect.

Our empirical analyses of NLSY79 data show that observable differences between high- and low-SES parents' cultural capital inputs lead to a socioeconomic gradient in children's educational attainment. In other words, cultural capital contributes to educational inequality. Moreover, and consistent with the CM theory but not with the CR theory, we find that hypothetically increasing cultural capital inputs among low-SES parents who provide low inputs (Scenario A) would lead to a larger reduction in educational inequality than hypothetically decreasing it by the same magnitude among high-SES parents who provide high inputs (Scenario B). These counterfactual results, which are based on NLSY79 data, illustrate that the return to cultural capital is asymmetric in the sense of being higher for low-SES children (who tend to occupy schooling environments with little cultural capital) than for high-SES children (who tend to occupy schooling environments with high levels of cultural capital). The results are also consistent with other research that has found that at the micro level, the effect of cultural capital on academic achievement is higher for low-SES children than for high-SES children (Andersen and Jæger 2015; Aschaffenburg and Maas 1997; Dumais 2006). A mechanism that might account for our findings is that cultural capital operates differently as a positional good in different schooling environments, thereby leading to different returns to cultural capital. Although we cannot test this hypothesis directly in this article, we encourage future research that analyzes whether children's "cultural capital rank" (i.e., their relative position within the distribution of cultural capital in their schools) is more important than their absolute level of cultural capital.

Our results have implications for cultural capital research and may inform policies to reduce educational inequality. In particular, our results point to the relevance of analyzing how cultural capital shapes educational inequality at the macro level. Although in the CR and CM theories cultural capital is transmitted 
from parents to children at the micro level, the ambition of both theories is to explain the persistence of educational inequality at the macro level. At present, we have only little evidence on this important issue, and we encourage future research that links the transmission of cultural capital at the individual level to educational inequality at the macro level. For example, it would be interesting to replicate our counterfactual analyses in other countries and analyze if differences in institutional characteristics (for example, in educational systems) might account for cross-national differences in the extent to which cultural capital shapes educational inequality.

Before discussing policy implications, we would like to highlight two limitations in our analysis. The first limitation is that our counterfactual design includes only two SES groups and two cultural capital input states. We kept the design deliberately simple in order to make the empirical analysis feasible. However, in theory, we could extend our counterfactual design to a more complex setup without a loss of generality. We chose not to do so in the current analysis because of our low sample size. An implication of this decision is that our estimates of the extent to which cultural capital accounts for the SES gradient in educational attainment are conservative because having more groups would enable us to identify more heterogeneous SES and cultural capital input groups in the population.

The second limitation is that we treat cultural capital as a one-dimensional concept. This was also done to simplify the analysis, but we could extend the counterfactual analysis to consider the equalizing effect of multiple aspects of cultural capital (familiarity with legitimate culture, reading, analytical skills, etc.). We leave this ambition for future work.

In these final sections, we address some policy implications of our findings. In addition to testing the implications of the CR and CM theories, we may also use the counterfactual approach to evaluate the equalizing potential of different policies. Although such interventions are hypothetical, we are aware of two real interventions that have attempted to increase cultural capital in the population.

First, Kisida et al. (2014) carried out an experimental study in the United States in which groups of students (most of whom were in grades 3-5) were randomly assigned to visit an art museum and (before the visit) to work with instructional materials related to art. Students were surveyed on average three weeks after the visit, and results showed that, compared to students in a control group, (especially) low-SES students who visited the museum were more likely to be interested in engaging with art museums and art in general and were also more likely to visit the museum in the future. Although a stronger interest in art is only one of several indicators of cultural capital, the authors also found that visiting the art museum increased students' ability to reflect critically on what they had learned, as measured via a written essay (Bowen, Greene, and Kisida 2013). Consequently, it may be that a policy intervention that creates cultural capital (especially among low-SES children, as in Scenario A) can bolster children's analytical skills in ways that shape educational inequality.

Second, Nagel et al. (2010) addressed the effect of a policy reform in the Netherlands that was designed to encourage cultural participation among adolescents. The reform made it mandatory for secondary-school students (age 14-17 years) 
to attend cultural events. Students received vouchers for cultural events (theatre, concerts, museums, etc.), and the authors compared patterns of cultural participation and cultural attitudes between students who were affected by the reform and a control group that was not affected. Results showed that students who were affected by the reform did not increase their cultural participation (or change their attitudes) when surveyed two to six years later. Results from this study suggest that it may be difficult to foster cultural capital in the long run or, alternatively, that interventions to foster cultural capital should be implemented when students are young (as was the case with Kisida et al. 2014) or should target low-SES students. Along with the two interventions discussed here, our counterfactual analysis shows that it is possible to analyze the impact of cultural capital at the macro level as well as the micro level, including its impact on educational inequality and policy interventions through which cultural capital might reduce (rather than increase) educational inequality.

\section{Notes}

1 Theoretically, we can think of these groups as comprising social classes or equivalent socioeconomic groupings. In the empirical analysis, we construct a summary measure of parents' SES based on income, socioeconomic position (Duncan SEI), and education. We could extend our counterfactual setup to include more than two SES groups (and, as we discuss, more than two groups of cultural capital inputs). However, in that case, the empirical setup (including the identification and estimation of counterfactual probabilities and covariances) would become very complex and, given our limited sample size, empirically unfeasible. This is why we limit the design to two SES (and cultural capital input) groups (see also the discussion).

2 Because the CYA supplement began in 1986, there is no information on cultural capital for children born between 1970 and 1974, and as a result, they are omitted from the analyses. Moreover, because we use several indicators to measure cultural capital inputs, we do not require individuals to have valid information on all of these indicators. We only omit individuals if they have no valid information on all indicators.

3 We estimate the inverse probability weight on the 5,974 CYA participants aged at least 25 years at the time of interview. The weight is based on information on sociodemographic characteristics. See Table 1 for a more detailed description of the weight.

4 Because our cultural capital indicators are discrete variables, we use polychoric correlations in the PCA. Moreover, because most respondents have missing information on some of the items used in the analysis, we use the pairwise correlation matrix as input in the PCA.

5 The retained principal components in the first step account for 43 percent, 31 percent, and 35 percent of the total variance for each age group, respectively. The principal component retained in the second step accounts for 68 percent of the total variance.

6 The NLSY79 did not collect information on income or other aspects of SES until 1978. This means that although we know if female respondents in the NLSY79 had any children when they were first interviewed (between age 14 and 22 years), we do not know their SES or the cultural capital inputs that they provided to their children. Moreover, because female respondents who already had any children in 1979 were drawn disproportionally from the low end of the SES distribution (Pirog, Jung, and Lee 2018), it is reasonable to 
assume that these mothers also had a higher likelihood of belonging to the group that provided low cultural capital inputs to children. Although we use weights to adjust for the selective nature of our analytical sample, a potential implication of missing data on SES and cultural capital for some low-SES children in our sample is that we understimate the extent to which cultural capital accounts for the SES gradient in educational attainment, which we report. We return to this point in the discussion.

7 We conducted a series of sensitivity analyses to check the robustness of our overall results. First, we added a measure of the children's cognitive ability to the models and examined changes in our predictions. Second, we conducted the analyses without using any weights. In all scenarios, the results were virtually identical to those reported here.

\section{References}

Andersen, Ida G., and Mads M. Jæger. 2015. “Cultural Capital in Context: Heterogeneous Returns to Cultural Capital across Schooling Environments." Social Science Research 50:177-88. https://doi.org/10.1016/j.ssresearch.2014.11.015.

Aschaffenburg, Karen, and Ineke Maas. 1997. “Cultural and Educational Careers: The Dynamics of Social Reproduction." American Sociological Review 62:573-87. https://doi . org/10.2307/2657427.

Bourdieu, Pierre. 1977a. "Cultural Reproduction and Social Reproduction." Pp. 487-511 in Power and Ideology in Education, edited by J. Karabel and A. H. Halsey. New York, NY: Oxford University Press.

Bourdieu, Pierre. 1977b. Reproduction in Education, Society, Culture. Beverly Hills, CA: Sage.

Bourdieu, Pierre. 1984. Distinction: A Social Critique of the Judgement of Taste. Cambridge, MA: Harvard University Press.

Bourdieu, Pierre. 1986. “The Forms of Capital." Pp. 241-58 in Handbook of Theory and Research in the Sociology of Education, edited by J. G. Richardson. New York, NY: Greenwood Press.

Bourdieu, Pierre, and Jean-Claude Passeron. 1990. Reproduction in Education, Society and Culture. London, United Kingdom: Sage.

Bowen, Daniel H., Jay P. Greene, and Brian Kisida. 2013. "Learning to Think Critically: A Visual Arts Experiment." Educational Researcher 43:37-44. https://doi .org/10.3102/ $0013189 \times 13512675$.

Covay, Elizabeth, and William Carbonaro. 2010. "After the Bell: Participation in Extracurricular Activities, Classroom Behavior, and Academic Achievement." Sociology of Education 83:20-45. https://doi.org/10.1177/0038040709356565.

Daloz, Jean-Pascal. 2013. Rethinking Social Distinction. Basingstoke, United Kingdom: Palgrave Macmillan. https://doi .org/10.1057/9781137316417.

de Graaf, Nan Dirk, Paul M. de Graaf, and Gerbert Kraaykamp. 2000. “Parental Cultural Capital and Educational Attainment in the Netherlands: A Refinement of the Cultural Capital Perspective." Sociology of Education 73:92-111. https://doi .org/10.2307/2673239.

DiMaggio, Paul. 1982. “Cultural Capital and School Success: The Impact of Status Culture Participation on the Grades of U.S. High School Students." American Sociological Review 47:189-201. https://doi.org/10.2307/2094962.

Dumais, Susan A. 2006. "Early Childhood Cultural Capital, Parental Habitus, and Teachers' Perceptions." Poetics 34:83-107. https://doi.org/10.1016/j poetic. 2005.09.003. 
Gaddis, S. Michael. 2013. "The Influence of Habitus in the Relationship between Cultural Capital and Academic Achievement." Social Science Research 42:1-13. https: //doi .org/ 10.1016/j.ssresearch.2012.08.002.

Georg, Werner. 2004. "Cultural Capital and Social Inequality in the Life Course." European Sociological Review 20:333-44. https://doi .org/10.1093/esr/jch028.

Fishman, Robert M., and Omar Lizardo. 2013. "How Macro-Historical Change Shapes Cultural Taste: Legacies of Democratization in Spain and Portugal." American Sociological Review 78:213-23. https://doi .org/10.1177/0003122413478816.

Heckman, James J. 1990. “Varieties of Selection Bias." American Economic Review 80:313-8. https://www.jstor.org/stable/2006591.

Jæger, Mads Meier. 2011. “Does Cultural Capital Really Affect Academic Achievement? New Evidence from Combined Sibling and Panel Data." Sociology of Education 84:281-98. https://doi.org/10.1177/0038040711417010.

Jæger, Mads Meier, and Richard Breen. 2016. "A Dynamic Model of Cultural Reproduction." American Journal of Sociology 121:1079-115. https : //doi . org/10 . 1086/684012.

Kaufman, Jason, and Jay Gabler. 2004. "Cultural Capital and the Extracurricular Activities of Girls and Boys in the College Attainment Process." Poetics 32:145-68. https: //doi .org/ $10.1016 / j$. poetic. 2004.02.001.

Kingston, Paul M. 2001. "The Unfulfilled Promise of Cultural Capital Theory." Sociology of Education 74:88-99. https://doi.org/10.2307/2673255.

Kisida, Brian, Jay P. Greene, and Daniel H. Bowen. 2014. “Creating Cultural Consumers: The Dynamics of Cultural Capital Acquisition." Sociology of Education 87:281-95. https : //doi.org/10.1177/0038040714549076.

Kraaykamp, Gerbert, and Koen van Eijck. 2010. “The Intergenerational Reproduction of Cultural Capital: A Threefold Perspective." Social Forces 89:209-31. https://doi .org/ 10.1353 /sof. 2010.0087 .

Lamont, Michele, and Annette Lareau. 1988. "Cultural Capital: Allusions, Gaps and Glissandos in Recent Theoretical Developments." Sociological Theory 6:153-68. https: //doi .org/10.2307/202113.

Lancee, Bram, and Herman van de Werfhorst. 2012. "Income Inequality and Participation: A Comparison of 24 Countries." Social Science Research 41:1166-78. https : //doi .org/10. 1016/j.ssresearch.2012.04.005.

Lareau, Annette. 2003. Unequal Childhoods. Class, Race, and Family Life. Berkeley, CA: University of California Press.

Lee, Jung-Sook, and Matasha K. Bowen. 2006. "Parent Involvement, Cultural Capital, and the Achievement Gap Among Elementary School Children." American Educational Research Journal 43:193-218. https: //doi .org/10.3102/00028312043002193.

Lizardo, Omar. 2006. "How Cultural Tastes Shape Personal Networks." American Sociological Review 71:778-807. https://doi.org/10.1177/000312240607100504.

Lizardo, Omar, and Sara Skiles. 2015. “After Omnivorousness: Is Bourdieu Still Relevant?” Pp. 90-103 in Handbook of the Sociology of Art and Culture, edited by L. Hanquinet and M. Savage. London, United Kingdom: Routledge.

Lucas, Samuel R. 2001. “Effectively Maintained Inequality: Education Transitions, Track Mobility, and Social Background Effects." American Journal of Sociology 106:1642-90. https://doi.org/10.1086/321300.

Lucas, Samuel R. 2017. “Effectively Maintained Inequality: An Introduction." American Behavioral Scientist 61:3-7. https : //doi .org/10.1177/0002764216682992. 
Maddala, Gangadharrao Soundalyarao. 1983. Limited-Dependent and Qualitative Variables in Econometrics. Cambridge, United Kingdom: Cambridge University Press. https: //doi.org/10.1017/CB09780511810176.

Mare, Robert D. 2011. "A Multigenerational View of Inequality." Demography 48:1-23. https://doi.org/10.1007/s13524-011-0014-7.

Mare, Robert D., and Christopher Winship. 1988. “Endogenous Switching Regression Models for the Causes and Effects of Discrete Variables." Pp. 132-60 in Common Problems in Quantitative Social Research, edited by J. S. Long. New York, NY: Sage.

Nagel, Ineke, Marie-Louise Damen, and Folkert Haanstra. 2010. “The Arts Course CKV1 and Cultural Participation in the Netherlands." Poetics 38:365-85. https://doi .org/10. $1016 / j$. poetic . 2010.05.003.

Pirog, Maureen A., Haeil Jung, and Daewoo Lee. 2018. "The Changing Face of Teenage Parenthood in the United States: Evidence from NLSY79 and NLSY97." Child Youth Care Forum 47:317-42. https://doi .org/10.1007/s10566-017-9417-y.

Roksa, Josipa, and Daniel Potter. 2011. "Parenting and Academic Achievement. Intergenerational Transmission of Educational Advantage." Sociology of Education 84:299-321. https://doi.org/10.1177/0038040711417013.

Sullivan, Alice. 2002. "Bourdieu and Education: How Useful Is Bourdieu's Theory for Researchers?" The Netherlands' Journal of Social Sciences 38:144-66.

Tramonte, Lucia, and J. Douglas Willms. 2010. "Cultural Capital and Its Effects on Education Outcomes." Economics of Education Review 29:200-13. https://doi.org/10.1016/j. econedurev.2009.06.003.

van de Werfhorst, Herman G. 2010. “Cultural Capital: Strengths, Weaknesses and Two Advancements." British Journal of Sociology of Education 31:157-69. https ://doi .org/10. 1080/01425690903539065.

Warren, John R., and Robert M. Hauser. 1997. “Social Stratification across Three Generations: New Evidence from the Wisconsin Longitudinal Study." American Sociological Review 62:561-72. https://doi .org/10.2307/2657426.

Weininger, Elliot B., Annette Lareau, and Dalton Conley. 2015. “What Money Doesn't Buy: Class Resources and Children's Participation in Organized Extraxurricular Activities." Social Forces 94:479-503. https: //doi .org/10.1093/sf/sov071.

Yaish, Meir, and Tally Katz-Gerro. 2012. "Disentangling 'Cultural Capital': The Consequences of Cultural and Economic Resources for Taste and Participation." European Sociological Review 28:169-85. https://doi.org/10.1093/esr/jcq056.

Acknowledgments: We presented this article at the 2015 Research Committee 28 meeting at Tilburg University and at several research seminars at the University of Copenhagen. We thank the participants at these events for their excellent comments. The research leading to the results presented in this article has received funding from the European Research Council (ERC) under the European Union's Seventh Framework Programme (FP/2007-2013) and ERC grant 312906.

Mads Meier Jæger: Department of Sociology, University of Copenhagen. E-mail: mmj@soc.ku.dk.

Kristian Karlson: Department of Sociology, University of Copenhagen. E-mail: kbk@soc.ku.dk. 